\title{
Randomised trial of two pharmacological methods of bowel preparation for day case colonoscopy
}

\author{
Anne Pinfield, Mark D Stringer
}

\begin{abstract}
Aims-To undertake a prospective, single blind, randomised trial comparing the efficacy and tolerance of two outpatient colonoscopy bowel preparation regimens.

Methods-Patients aged between 18 months and 16 years being admitted for day case colonoscopy were allocated randomly to receive either Picolax (an oral, sugar free powder containing sodium picosulphate $10 \mathrm{mg} / \mathrm{sachet}$ with magnesium citrate) and clear fluids or bisacodyl tablets with an unrestricted diet and a phosphate enema just before colonoscopy. Patient compliance, bowel frequency, and associated symptoms were recorded, and the adequacy of the bowel preparation was assessed in a blinded manner.

Results-63 of 66 patients completed the trial. Mean age, mean weight, extent of colonoscopy, and distribution of underlying pathology were similar in both groups. Bowel preparation was good or excellent in all of the patients in the Picolax group $(n=32)$ compared with 22 patients in the bisacodyl/phosphate enema group $(\mathbf{n}=31)$. The latter group experienced more abdominal discomfort during bowel preparation but three of the Picolax group vomited and the lack of solid food distressed some children.

Conclusions-All bowel preparation methods have limitations and unpleasant side effects but the use of Picolax and clear fluids proved superior to bisacodyl tablets and a phosphate enema in children undergoing day case colonoscopy.

(Arch Dis Child 1999;80:181-183)
\end{abstract}

Keywords: colonoscopy; bowel preparation; randomised trial

Colonoscopy is now a relatively routine investigation in children with rectal bleeding and suspected inflammatory bowel disease, and in selected patients with chronic diarrhoea and other abdominal symptoms. Adequate bowel preparation is critical to the success of the examination and a variety of regimens exist. These can be classified broadly into mechanical and pharmacological methods, although many are combinations of both. Traditional mechanical bowel preparation involves whole gut irrigation with large volumes of electrolyte lavage solution; this is very unpleasant for the child, and frequently needs to be administered via a nasogastric tube in hospital. In 1995, Abubakar et al evaluated the use of an outpatient bowel preparation comprising a combination of an unrestricted diet, oral bisacodyl, and a phosphate enema. ${ }^{1}$ They assessed 30 children and deemed the bowel preparation to be excellent in 26 children. The purpose of our study was to undertake a prospective, single blind, randomised trial comparing the efficacy and tolerance of this regimen with our standard outpatient bowel preparation method of Picolax and clear fluids.

\section{Methods}

All patients aged between 18 months and 16 years referred to the Leeds General Infirmary between May 1996 and November 1997 for day case colonoscopy were invited to participate in a randomised trial of bowel preparation. Patients undergoing colonoscopy as inpatients or as non-elective procedures were excluded from the study. After informed consent, subjects were allocated randomly to receive one of two preparations, which were administered at home as directed by the paediatric continence nurse (AP).

REGIMEN 1

Picolax was given as two oral doses 24 and 18 hours before colonoscopy. During this 24 hour period the patient was allowed no solid food but a liberal intake of clear fluids was encouraged up to three hours before the anaesthetic. Clear fluids included flavoured squashes, "flat" carbonated drinks, ice lollies, fruit jellies, clear soup, and clear stock drinks. Older children were allowed boiled sweets. Picolax dosages varied according to age and weight - a quarter of a sachet times two for those under 2 years of age, a half sachet times two for 2-5 year olds, one sachet and a half sachet for 5-10 year olds, and one sachet times two in those older than 10 years. Picolax is a proprietary name (Ferring Pharmaceuticals Limited, Middlesex, UK) for an oral, sugar free powder containing sodium picosulphate $10 \mathrm{mg} / \mathrm{sach}$ et with magnesium citrate.

\section{REGIMEN 2}

Bisacodyl tablets and a phosphate enema were administered as described by Abubakar et al. ${ }^{1}$ With this preparation, patients were allowed an unrestricted diet up until six hours before anaesthesia and clear fluids until three hours before. For 1-5 year olds, bisacodyl (Dulcolax; Boehringer Ingelheim, Berkshire, UK) $5 \mathrm{mg}$ was given each morning for two days before the endoscopy and half a Fletcher's enema $(64 \mathrm{ml})$ was given on the morning of colonoscopy at least one hour before the procedure. For children aged over 5 years, bisacodyl $10 \mathrm{mg}$ in the morning was given for two days before and 
Table 1 Comparison of bowel preparation results after Picolax and bisacodyl/phosphate enema

\begin{tabular}{llll}
\hline & Picolax $(n=32)$ & Bisacodyl $(n=31)$ & Significance \\
\hline Mean (range) age (years) & $9.1(2-16)$ & $10.0(3-15)$ & $\mathrm{NS}$ \\
Mean (SD) weight (kg) & $29.0(12.2)$ & $32.1(12.4)$ & $\mathrm{NS}$ \\
Ileal examination & $81 \%$ & $81 \%$ & \\
Bowel preparation score & 0 & 9 & $\chi^{2}=13.14$ \\
1 & 15 & 15 & $\mathrm{df}=2$ \\
2 & 17 & 7 & $\mathrm{p}<0.01$ \\
3 & & & \\
\hline
\end{tabular}

Table 2 Comparison of acceptability of the two bowel preparation regimens

\begin{tabular}{llll}
\hline & $\begin{array}{l}\text { Picolax group } \\
(n=32)\end{array}$ & $\begin{array}{l}\text { Bisacodyl group } \\
(n=31)\end{array}$ & Significance \\
\hline Compliance with medication & Excellent & Excellent & $\chi^{2}=9.4$ \\
No abdominal discomfort & 25 & 13 & $\mathrm{~d}=2$ \\
Mild abdominal discomfort & 6 & 12 & $\mathrm{p}<0.01$ \\
Abdominal pain & 1 & 6 & \\
Vomiting & $3^{\star}$ & 0 & \\
Number with episodes of faecal incontinence & 6 & 8 & \\
Mean (SD) number of bowel actions & $8.3(3.8)$ in & $10.4(5.4)$ in & \\
Moderate/severe distress owing to lack of & $24 \mathrm{~h}$ & $48 \mathrm{~h}$ & \\
$\quad$ solid food & $5 / 1$ & & \\
Distress by enema† & & 6 & \\
\hline
\end{tabular}

${ }^{\star}$ Seven children complained of nausea mainly at the time of drinking the medicine. †Minor distress in all cases.

a complete Fletcher's phosphate enema $(128 \mathrm{ml})$ was given on the morning of colonoscopy at least one hour before the procedure. Younger children were given the tablet disguised in a spoonful of yoghurt, jam, or cereal.

COLONOSCOPY

Although not actually necessary during this study, it is our practise to discontinue oral iron preparations one week before colonoscopy. Participating patients were allocated randomly to each preparation using a sealed envelope system. A diary detailing the patient's compliance with medication, bowel actions, associated symptoms and any soiling episodes was completed by child and parent. On the day of admission to the day care unit, parent and child were interviewed by the continence nurse using a structured questionnaire, and the bowel preparation diary was collected.

All colonoscopies were carried out under general anaesthesia by a single operator (MDS) using a paediatric fibreoptic colonoscope (Olympus PCF 20) and mucosal grasp biopsies were taken routinely at multiple sites from the distal ileum to the rectum. Antibiotic prophylaxis was given to children with congenital heart lesions and immunosuppressed patients. The adequacy of bowel preparation was assessed as follows with the endoscopist completely blind to the method of bowel preparation: grade 1, poor preparation; grade 2 , good preparation, small amounts of faecal material in scattered locations removable by suctioning and not preventing satisfactory visualisation of bowel mucosa; grade 3, excellent preparation, no faecal material. Relevant clinical and demographic details were also recorded.

Local research ethics committee approval was obtained. Parents (and patients older than 5-6 years) were provided with both verbal and written information about our study. The trial generated no conflict of interest.

STATISTICAL ANALYSIS

Statistical analysis was by conventional parametric statistics for normally distributed data and by $\chi^{2}$ for comparison of bowel preparation scores.

\section{Results}

During the study period, a total of 90 children were referred for colonoscopy to the Leeds General Infirmary. Fifteen were admitted to hospital and, therefore, did not meet the day case trial entry criterion, one was outside the specified age range, and four required only limited left colonic examinations not requiring full bowel preparation. Of the 70 children eligible for the study, 66 were invited to participate in the trial, all of whom were recruited. Sixty three children ( 34 boys, 29 girls) completed the trial; three cancelled and rescheduled their investigation for reasons unrelated to bowel preparation and they were excluded from further analysis. One patient who was randomised to the bisacodyl group subsequently expressed a preference for Picolax bowel preparation and was analysed in the bisacodyl group on an intention to treat basis.

There were 31 patients randomised to the bisacodyl group and 32 to the Picolax group. Colonoscopic diagnostic categories were distributed similarly in both groups and included inflammatory bowel disease $(n=13)$; colonic polyps $(n=8)$, two of which were removed by snare polypectomy; allergic colitis $(n=6)$; and miscellaneous pathology $(n=8)$, including vascular, lymphoid, and infective conditions. There was no significant pathology (apart from threadworm and anal pathology) in 28 cases.

Table 3 Bowel preparation methods for paediatric colnoscopy

\begin{tabular}{|c|c|c|}
\hline Method & Major limitations & Reference \\
\hline Oral bisacodyl, phosphate enema & Efficacy of preparation/need for enema & Abubakar et al (1995) ${ }^{1}$ \\
\hline \multirow[t]{4}{*}{ Electrolyte lavage solution (polyethylene glycol/electrolyte mixture) } & Nasogastric tube often required & Tolia et al $(1984)^{2}$ \\
\hline & Nausea and vomiting common & Sondheimer et al (1991) ${ }^{3}$ \\
\hline & Abdominal cramps & Gremse et al $(1996)^{4}$ \\
\hline & Risk of hypothermia unless warmed & da Silva et al $(1997)^{5}$ \\
\hline \multirow{3}{*}{$\begin{array}{l}\text { Clear fluids, senna, and oral bisacodyl, or polyethylene glycol lavage } \\
\text { solution via nasogastric tube, and saline enemas }\end{array}$} & & \\
\hline & Combined disadvantages (see above) & Israel et al $(1994)^{6}$ \\
\hline & Lack of solid food and tendency to vomit & $\begin{array}{l}\text { Evans et al }(1989)^{7} \\
\text { Williams and Nicholls }(1994)^{8}\end{array}$ \\
\hline Picolax, senna, and clear fluids ( \pm enema) & 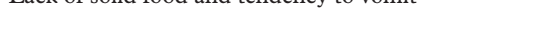 & Gremse et al (1996) \\
\hline Oral sodium phosphate solution & Hyperphosphataemia & da Silva et al $(1997)^{5}$ \\
\hline \multirow[t]{2}{*}{ Senna syrup (X-prep) and enema(s) \pm clear fluids } & Need for enema & Williams et al $(1982)^{9}$ \\
\hline & \pm Lack of solid food & Trautwein et al $(1996)^{10}$ \\
\hline $\begin{array}{l}\text { Senna syrup and magnesium citrate, or polyethylene glycol electrolyte } \\
\text { solution, or isotonic mannitol }(5 \%)\end{array}$ & $\begin{array}{l}\text { Risk of explosion with mannitol (contraindicated with } \\
\text { polypectomy) }\end{array}$ & Milla and Williams $(1995)^{11}$ \\
\hline
\end{tabular}


BOWEL PREPARATION

Owing to an administrative error, 14 of the 28 patients older than 5 years in the bisacodyl group received only half a phosphate enema instead of a whole one; the remainder received their correct medication. However, because the bowel preparation scores were actually slightly better in this subset (mean grade $2.07 v 1.82$ ) they have been retained for comparison with the Picolax group. Table 1 gives the bowel preparation results.

TOLERANCE/SIDE EFFECTS

Table 2 details the acceptability of the bowel preparation methods. Distress in the child was assessed subjectively by the parent.

\section{Discussion}

Bowel preparation is a critical part of successful colonoscopy and in the evaluation of such regimens it is important to consider both the cleanliness of the colon and the acceptability to the child. A variety of different methods have been used in paediatric colonoscopy (table 3) but there have been few randomised trials. ${ }^{1-11} \mathrm{~A}$ recent study attempted to evaluate 22 different combinations of laxatives, lavage solutions, suppositories, and enemas in 52 patients! ${ }^{12}$ Picolax has been used successfully before in conjunction with senna syrup and no major complications were reported, although these authors used a second dose three hours before the endoscopy. ${ }^{7}$ Bowel cleansing was deemed to have been unsatisfactory in only $5 \%$ of examinations. In contrast, regimens based on oral sodium phosphate solution or polyethylene glycol electrolyte lavage usually achieve good to excellent bowel preparation in only $70-80 \%$ of cases. $^{45}$

In our trial, the results of home bowel preparation with a bisacodyl/phosphate enema regimen were comparable with those reported previously by Abubakar et al. ${ }^{1}$ Patients were of similar age and disease distribution and the frequency of recorded bowel actions was also equivalent (a mean of 10.4 bowel actions in 48 hours compared with 4.9 in 24 hours). However, using the same scoring system, Abubakar and colleagues considered the bowel preparation to be good or excellent in all their patients whereas this was the case in only 22 of 31 patients in our trial. The use of half a phosphate enema instead of a whole one in some patients is clearly not the cause of this difference because the bowel preparation scores were slightly better in the former patients. The explanation may be related partly to the fact that in their study, colonoscopies were only as far as the ascending colon or caecum, whereas $81 \%$ of our cases underwent ileoscopy; it was apparent in retrospect that many of the poor bowel preparations in the bisacodyl group were related to relatively large amounts of faecal material in the right colon in the presence of a clean left colon.
In our trial, Picolax produced significantly better bowel preparation for colonoscopy (all good or excellent) than the bisacodyl/phosphate enema regimen (22 of 31 good or excellent). This was achieved with significantly less abdominal discomfort but three children vomited, mostly when drinking the medicine. Judicious flavouring and chilling might help to improve the palatability of the medication. There were similar levels of distress in both groups caused by lack of solid food and the use of an enema, respectively. It was also noted that children undergoing preparation with the bisacodyl/ phosphate enema regimen tended to take two days off school for bowel preparation (in addition to the day case admission), whereas those having Picolax needed only one. This is especially important in those children with inflammatory bowel disease who might need repeated examinations. Although not required during this trial, on rare occasions we have found it necessary to give a patient intravenous fluid at the time of their colonoscopy if they appeared dehydrated and this might be more likely with Picolax because it produces more rapid colon cleansing. While we recommend Picolax for bowel preparation before total colonoscopy in children, the bisacodyl/ phosphate enema regimen might have a useful role in selected patients requiring more limited examinations.

We wish to acknowledge the expertise of our anaesthetic colleagues, Drs P McHugh and J Brown and the nursing staff of the Children's Day Care Unit who helped to administer this trial.

1 Abubakar K, Goggin N, Gormally S, Durnin M, Drumm B. Preparing the bowel for colonoscopy. Arch Dis Child 1995;73:459-61.

2 Tolia V, Fleming S, Dubois R. Use of Golytely in children and adolescents. F Pediatr Gastroenterol Nutr 1984;3:48670 .

3 Sondheimer JM, Sokol RJ, Taylor SF, Silverman A, Zelasney B. Safety, efficacy and tolerance of intestinal lavage in pediatric patients undergoing diagnostic colonoscopy. $\mathcal{F}$ Pediatr 1991;119:148-52.

4 Gremse DA, Sacks AI, Raines S. Comparison of oral sodium phosphate to polyethylene glycol-based solution for bowel preparation for colonoscopy in children. 7 Pediatr Gastroenterol Nutr 1996;23:586-90.

5 da Silva MM, Briars GL, Patrick MK, Cleghorn GJ, Shepherd RW. Colonoscopy preparation in children: safety, efficacy, and tolerance of high- versus low-volume cleansing cacy, and tolerance of high- versus low-volume clean
methods. F Pediatr Gastroenterol Nutr 1997;24:33-7.

6 Israel DM, McLain BI, Hassall E. Successful pancolonoscopy and ileoscopy in children. F Pediatr Gastroenterol Nutr 1994;19:283-9.

7 Evans M, Walker-Smith J, Williams C. Safety of Picolax in inflammatory bowel disease [letter]. BMF 1989;299:11012.

8 Williams CB, Nicholls S. Endoscopic features of chronic inflammatory bowel disease in childhood. Baillere's Clin Gastroenterol 1994;8:121-31.

9 Williams CB, Laage NJ, Campbell CA, et al. Total colonoscopy in children. Arch Dis Child 1982;57:49-53.

10 Trautwein AL, Vinitski LA, Peck SN. Bowel preparation before colonoscopy in the pediatric patient: a randomized study. Gastroenterology Nursing 1996;19:137-9.

11 Milla PJ, Williams CB. Colonoscopy. In: Spitz L, Coran AG, eds. Pediatric surgery, 5th ed. London: Chapman and Hall Medical, 1995:522-3.

12 Barrish JO, Gilger MA. Colon cleanout preparations in children and adolescents. Gastroenterology Nursing 1993;16: 106-9. 